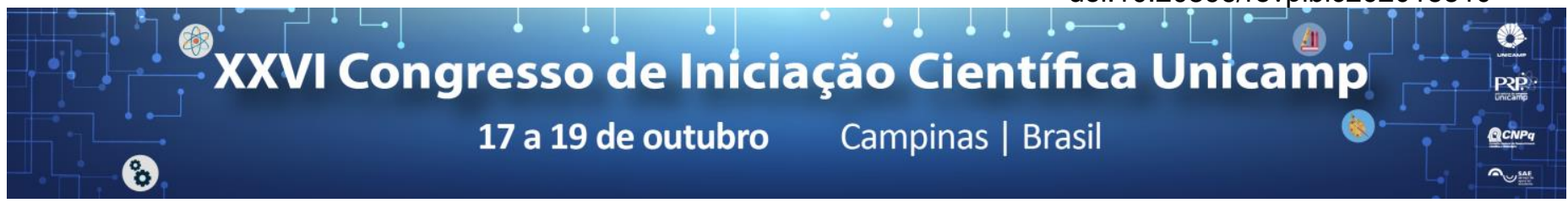

\title{
Análise da organização modular em quatro residencias projetadas por Frank Lloyd Wright.
}

\section{Leonardo Botene da Silva*, Ana Maria Tagliari Florio.}

\section{Resumo}

O objeto desta pesquisa são quatro projetos residenciais modernos desenhados por Frank Lloyd Wright concebidos a partir da ideia de projeto modulado. Foram selecionados quatro tipos de módulos adotados nas residências Usonian propostas por Wright após a década de 1930: o módulo retangular, residência Stanley Rosenbaum (1939); quadrado, residência Goetsch-Winckler (1939); triangular, residência Jorgine Boomer (1953); e radial, residência David Wright (1950).

\section{Palavras-chave:}

Residência moderna; Projeto modulado; Frank Lloyd Wright.

\section{Introdução}

As residências Usonian tiveram como características principais o fato de serem pequenas, moduladas e econômicas. Após a Grande Depressão norte-americana (1929), Wright se dedicou ao projeto e construção dessas casas com baixo custo até 1959, ano de sua morte. As Usonian Houses são residências projetadas a partir de um módulo que está presente em vários elementos do espaço e da forma.

A modulação geométrica pode ser de natureza estrutural; construtiva, baseada nos materiais; ou conceitual, estruturada com base em uma ideia de ordem estética ou formal. Geometria é a ideia geratriz que relaciona os elementos arquitetônicos e suas relações espaciais. $O$ módulo é uma figura geométrica que organiza e ao mesmo tempo proporciona liberdade no projeto. A análise gráfica permite identificar relações de traçados reguladores que ajudam a estruturar o raciocínio espacial, tanto por meio de eixos, como por meio de modulações e métricas.

Esta pesquisa tem o objetivo de analisar a adoção de cada módulo nos projetos selecionados. Pretende-se analisar individualmente cada projeto selecionado e elaborar uma tabela comparativa para destacar as peculiaridades e constantes nos projetos, enfatizando como o módulo organiza espaço e forma em cada projeto residencial selecionado.

\section{Resultados e Discussão}

Os redesenhos auxiliam na análise da modulação e suas implicações na escolha dos materiais e no partido de cada uma das residências. Assim, o redesenho dos projetos possibilitou a visualização e compreensão dos princípios defendidos pelo arquiteto como: gramática, integração, simplicidade, continuidade e plasticidade.

A pesquisa foi realizada a partir da leitura da bibliografia selecionada, do levantamento de textos e desenhos que auxiliassem no redesenho das residências.

Durante a pesquisa foram produzidos modelos digitais e físicos que auxiliaram no entendimento da modulação; redesenhos e análises, tendo como foco a planta baixa das residências pois, segundo o arquiteto, nela estão presentes ritmo, massa e proporção (WRIGHT, 1954) sendo um importante item para análise da geometria, do módulo e da coordenação modular.
Tabela 1. Síntese com alguns modelos e análises produzidos durante a pesquisa, ao menos um para cada objeto.

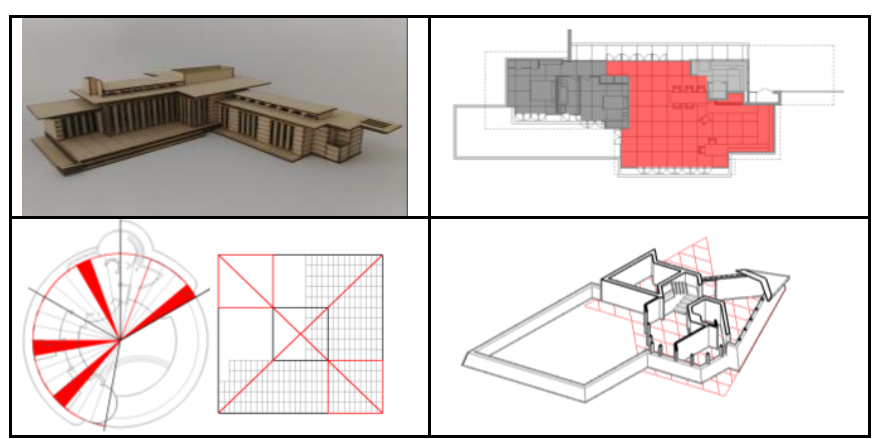

\section{Conclusões}

Conclui-se que a geometria de modulação e suas dimensões estão diretamente relacionadas com a escolha dos materiais utilizados, com a escala humana e com as características do entorno onde cada residência se situa. Embora o arquiteto nomeie sua arquitetura como "orgânica", é possível observar traços funcionalistas e racionalistas e seus projetos, como sugerem as análises.

Esta pesquisa proporcionou um claro entendimento da modulação e possibilitou que esse sistema fosse utilizado academicamente, especialmente em trabalhos de cunho social.

Os métodos de análise utilizados, bem como a experimentação constante do arquiteto em diversas formas e contextos, sugerem futuros desdobramentos para esta pesquisa.

\section{Agradecimentos}

Agradeço à Prof ${ }^{a}$. Dr ${ }^{a}$. Ana M. Tagliari Florio e ao PIBIC pela oportunidade e incentivo a esta pesquisa.

GREVEN, Hélio; BALDAUF, Adão; Alexandra Staudt Follmann. Introdução à coordenação modular da construção no Brasil: Uma abordagem atualizada. Porto Alegre: (Coleção Habitare, 9) ANTAC, 2007.

HOPPEN, Donald W. The seven ages of Frank Lloyd Wright: the creative process. New York: Dover Publications, 1998

TAGLIARI, Ana. Frank Lloyd Wright. Princípio, Espaço e Forma na Arquitetura Residencial. São Paulo: Annablume Editora, 2011.

WRIGHT, Frank Lloyd. The Natural House. New York: Horizon Press, 1954 